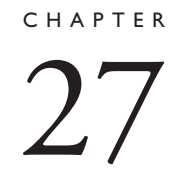

\title{
Resource Acquisition, Violence, and Evolutionary Consciousness
}

\author{
Gregory Gorelik, Todd K. Shackelford, and Viviana A. Weekes-Shackelford
}

\begin{abstract}
The evolution and development of adaptations result from the gradual selection and inheritance of traits and behaviors that better enable organisms to acquire and maintain resources needed for survival and reproduction. We argue that instances of individual, regional, and global violence are rooted in our adaptations to seek, acquire, maintain, and utilize limited resources, regardless of whether such adaptations are currently successful at doing so. However, violence is not the only strategy employed by organisms to acquire resources; cooperation, reciprocity, and social bonding are behaviors that may likewise prove useful in this endeavor. We speculate about how individual adaptations and their by-products may interact with the adaptations of other individuals and with societal and cultural phenomena, both violently and nonviolently. Finally, we discuss how individual decisions can affect higher level regional and global violence. Individual decisions carry moral weight for the individual in question and for society as a whole. We hope to convince readers that their personal decisions and behaviors have far-reaching consequences on the well-being of others and that an evolutionary consciousness may help us to understand the effects of our personal choices on the existence of individual- and group-level violence.
\end{abstract}

Key Words: evolution, violence, war, rape, resources, sexual selection, extended phenotype

\section{Introduction}

The scourge of brutal violence has gripped humanity from time immemorial. While writing this chapter, the "Arab Spring" uprising of individuals in opposition to ruling despots in North Africa and the Middle East has unleashed unimaginable violence that has left thousands dead. In Libya, Moammar Gadhafi and his supporters are raping and murdering their way through the populace in an attempt to hold onto the reins of power. Cell phone videos confiscated from Gadhafi loyalists depict the brutal physical and sexual torture of Libyan civilians. According to CNN (Razek, Ahmed, \& Sidner, 2011):

It [a confiscated video] shows two men in civilian clothes standing over a naked woman who is bent over with her face on the floor. The man standing behind her is sodomizing her with what appears to be a broomstick.

"I can't bear it! I can't bear it!" the woman cries.

"Let's push it farther," a male voice says off camera.

"No, no, that's enough!" the woman begs.

Eventually, one of the men puts his sock-covered 
foot on her face. In Arab culture, that is considered a major insult.

Farther east, a wave of protests across Syria has sparked genocidal retaliation from Bashar al-Assad's government. Men, women, and children are being tortured and killed for demanding their right to free expression. Hamza Ali al-Khateeb, a 13-yearold boy participating in anti government protests with his family and friends, was shot and tortured by Syrian Airforce Intelligence officers prior to his body being returned to his family. The Washington Post (Sly, 2011) reported that Hamza's...

... head was swollen, purple and disfigured. His body was a mess of welts, cigarette burns and wounds from bullets fired to injure, not kill. His kneecaps had

been smashed, his neck broken, his jaw shattered and his penis cut off.

In Norway, the worst mass shooting since World War II was perpetrated by a right-wing Christian extremist in reaction to the government's support of Muslim immigration and other multiculturalist policies. His bombing of downtown Oslo and his subsequent shooting rampage at a Labor Party youth camp left 76 dead (McLaughlin, 2011).

Meanwhile in Somalia, a widespread famine has led to the starvation and death of nearly 30,000 children and the malnourishment of 13 million Somalis. The situation is exacerbated by Somalia's high fertility rate and violent conflict between various Islamist militants, tribal warlords, and the federal government. Somalia thus exemplifies the fact that overpopulation and resource scarcity fuel much of global violence (Teague, 2011).

Students of history are well aware of the ubiquity of human brutality and sadism throughout the ages. As cited by Van Vugt (Chapter 17, this volume), warfare may have existed early on in human evolution, as anthropologists have uncovered mass graves of mostly male skeletons exhibiting blunt-force trauma dated to around 200,000 years ago (YA). In Provence, France, a rock etching dated to about 22,000 YA portrays a human figure embedded with projectile weapons (Livingstone Smith, Chapter 20, this volume), and numerous geological and archaeological findings from the southwest and northeast United States depict millennia of coalitional warfare between Native American tribes, especially during times of drought and other periods of resource scarcity (Lambert, Chapter 19, this volume). Modern history is bloodied with the horrors of World War I, World War II, the Holocaust, Soviet purges and gulags, the Korean War, the Vietnam War, the Cambodian Killing Fields, the first Gulf War, genocides in Bosnia, Kosovo, Rwanda, and Darfur, the Israeli-Palestinian conflict, and the US-led wars in Iraq and Afghanistan, to name a few.

Although death rates due to war, homicide, and other forms of violence have declined throughout the Western world in recent centuries (even if we include the bloody conflicts of the 20th century; Van Vugt, Chapter 17, this volume), the human capacity to destroy its own species and the rest of the ecosystem is unprecedented. Thus, our penchant to inflict unimaginable harm on one another has kept pace with advances in medicine and innovations in nutrition-yielding technologies. Unless violence is understood with the empirical and conceptual tools of modern science, and evolutionary science in particular, the near future of our species looks bleak.

In keeping with the themes of this volume, we advance an evolutionary perspective on human violence. In addition to discussing the evolutionary and developmental origins and abstract dynamics of individual violence, and violence within and between political, religious, ethnic, national, and other cultural groups, we speculate about the possible applications of evolutionary science to moral and practical choices within the personal domain, which may help one to develop what we term an "evolutionary consciousness." The application of scientific findings to practical matters of human life is not without peril, and the misuse of science to support racial, political, or religious movements is not unheard of. Nonetheless, findings within the evolutionary sciences can inform and guide individual and collective decisions regarding acts of physical and sexual violence. An evolutionary perspective provides a useful heuristic for scholars wishing to understand human violence because humans are biological beings who are related to, and have coevolved with, one another and with other species. Likewise, an evolutionary paradigm can enrich one's understanding of oneself and one's context.

\section{The Problem of Population}

In 1798, the English scholar Thomas Malthus published his landmark An Essay on the Principle of Population. Within it, Malthus posited his "great law of nature," which states that population levels cannot exceed levels of subsistence production. Thus, because populations grow hyperbolically, while means of production grow arithmetically, a point is inevitably reached at which there is no longer enough food to sustain the growing population. 
We now know that Malthus's laws are not immutable, in that population rates may not always surpass or even reach levels of food production, as is the case in many developed nations (Hopfenberg \& Pimentel, 2001). However, conflicts over access to limited nutritional and other reproductively relevant resources were a great selection pressure on human and nonhuman populations across evolutionary time. No wonder Malthus's ideas inspired Charles Darwin's formulation of natural selection as the creative factor in biological evolution in the following century. Darwin's addendum to Malthus states that because there are variations between individuals within a population, those individuals who are successful at competing for scarce resources outreproduce less successful individuals, and so pass on the very traits that led to their success. Thus, adaptations such as the heart and the brain are constructed across evolutionary time as randomly appearing variations are inherited that refine and improve an organism's ability to acquire reproductively relevant resources. From single-celled organisms competing for nutrients or hosts to complex multicellular eukaryotes such as plants competing for sunlight, evolutionary success is synonymous with the acquisition and use of resources needed for survival and reproduction, across many levels of analysis.

Reproductive success may be achieved by means other than direct reproduction. For example, helping genetic relatives to reproduce increases the likelihood that some of one's own genes are passed on to the next generation, regardless of whether one has offspring (Hamilton, 1964). This phenomenon may help to explain instances in which individuals sacrifice their lives for relatives, and pseudo-relatives (or "fictive kin") in times of conflict and war, or during acts of terrorism on behalf of one's actual (or nominal) brothers and sisters. As a result of such acts, the self-sacrificed individual's relatives may acquire reproductively useful resources (see Sosis, Phillips, \& Alcorta, Chapter 14, this volume). This phenomenon may likewise explain instances of self-inflicted violence and suicide, which is likely to affect individuals of low reproductive value but with fertile family members in need of useful resources that the suicidal individual may be consuming (see Brown \& Brown, Chapter 9, this volume).

In this chapter, we apply concepts from evolutionary biology and evolutionary psychology to examine some of the evolved functions of the human mind that are manifested as violent behaviors. Our underlying theme is that violence served the function of enabling organisms to acquire reproductively relevant resources in ancestral environments. For our ancestors, possession of resources served to foster two related, though somewhat orthogonal, reproductive goals. The first was to survive long enough to reproduce. Some of the resources needed to fulfill this goal are food, shelter, warmth, and safe environments. Thus, much of violent conflict in ancestral and modern humans, both within and between groups, can be traced to the scarcity of such resources, all essential for survival. Not so obvious (except to students of evolutionary biology) is the second goal that the acquisition of resources fostered: the chance to acquire a mate-a resource in itself. Resources needed to fulfill this goal are numerous and vary across time and place. Some of the requisite resources are territory, allies, social dominance, status, weaponry, precious natural or human-made objects such as diamonds, body decorations and accessories, and currency. The reason that organisms compete for resources that are seemingly inessential for survival is attributable to sexual selection, a concept from evolutionary biology which posits that survival is not the only hurdle that organisms must surmount to reproduce; they must also defeat their reproductive rivals and attract members of the other sex. Defeating rivals often entails the evolution of traits supporting physical strength and social dominance (which may explain why men are, on average, larger and more violent than women-a correlate of high testosterone; Buss \& Shackelford, 1997; Kolbert \& Crothers, 2003). Such traits may also be considered attractive by members of the other sex. Thus, although human violence is mostly perpetrated by men of reproductive age against other men of reproductive age, the fact that many women find dominant and aggressive men attractive suggests that no one sex is to blame for the evolution of violent behavior in our species.

In the natural world, conflicts over resources are usually more violent between males than between females. This was the case in human ancestral environments and remains so today (Kruger \& Fitzgerald, Chapter 10, this volume). The reason for this is that in most sexually reproducing species, males are less likely to invest in parenting than are females (Trivers, 1972). As a result, it is often in a male's best interest to compete more vigorously with other males for sexual access to females, as he is not burdened by gestation, lactation, and other costs of offspring production and rearing, and can be more reproductively successful by copulating with many females. Females, however, pay higher reproductive costs than males and so avoid indiscriminate mating 
and injury-causing competition with rival females. Human males are notable in that they make better fathers than most other primates. Thus, for an ancestral woman, mating with a man of low mate value or who was unlikely to assist in childrearing could have imperiled a woman's reproductive prospects by causing injury or death to her child, perhaps due to starvation, disease, predators, or violent conspecifics. Therefore, men are likely to use violence against other men when competing for both short-term mates and long-term mates.

Due to differences between ancestral environments and modern environments, what was adaptive for our ancestors then may not be adaptive for us now. Even if human violence serves an evolved function in modern environments, this does not make it morally defensible. Nevertheless, if we take a cursory look at current local and global conflicts, most are waged over resources. Thus, conflicts over water reservoirs, oil pipelines, and gold and diamond deposits often involve savage forms of violence. It is also easy to see (especially after the 2008 worldwide economic crisis) how more relational or "structural" forms of violence (see Dess, Chapter 26, this volume) over monetary and other intangible economic resources (such as subprime mortgages) may be responsible for much social unrest. This last point suggests that human violence may not only result from struggles over material resources but symbolic ones as well. Therefore, many religiously inspired acts of violence and war may be rooted in a struggle for access to the "belief-sphere" for one's god or gods over the god or gods of others. Of course, religious conflicts may sometimes be about access to tangible resources such as food, territory, and mates, but they are likely to be especially intractable when there is a lack of compromise on "sacred values" by the parties involved (see Sosis et al., Chapter 14 , this volume). Next, we discuss the developmental dynamics of violent conflict in humans. To understand the evolution of human violence, its emergence must be tracked across an individual's life span-from its prenatal origins to its global consequences. Although violent behavior varies individually and contextually, its emergence in conflicts over reproductively relevant resources is what unites its varying characteristics.

\section{The Development of Human Violence}

Biological adaptations are not preformed but undergo a dynamic and intricate process of development that belies the nature-nurture dichotomy. A complex biological organism begins its existence as an undifferentiated cell. This cell soon divides into two daughter cells. In turn, those two cells divide into two cells, and so on. Throughout this process, the cells differentiate in structure and function into the myriad organs and organ systems that comprise an individual organism. The developmental course of a cell is dependent on where it is physically located within the developing organism and on the timing of its replicative cycle (Carroll, 2005). Although all nongametic cells are genetic clones of one another, they assume different structural and physiological characteristics due to the differential effects of the developmental context upon each cell and its genome. Thus, a biological adaptation (which is a result of natural selection) is dependent upon the developmental context for its emergence and functionality (see Tooby \& Cosmides, 1992, for an early and comprehensive argument for the central role of development in understanding adaptations). Factors extrinsic to the developing organism, such as the mother's diet, exposure to biochemicals, and other ecological factors, affect the development of an organism and its adaptive properties (Bjorklund \& Pellegrini, 2002; Carroll, 2005). The developmental context is not limited to extragenetic factors, as a gene's expression is dependent on the action of other genes that either suppress or enhance its effects (Carroll, 2005). Interestingly, an organism's own behavior is pivotal for the normal development of species-typical adaptations. For example, a fetus's flailing of its arms and legs is essential for the proper development of its musculoskeletal structures (Rodriguez, Palacios, Garcia-Alix, Pator, \& Paniagua, 1988). Likewise, an infant's development of vision, audition, and facial recognition is dependent on its exposure to sights, sounds, and faces (Chang \& Merzenich, 2003; Fagiolini, Pzzorusso, Berardi, Domenici, \& Maffei, 1994; Nelson, 2001). Adaptations to violent conflict are no different.

Organisms that were successful at acquiring reproductively relevant resources survived long enough to reproduce and thereby pass on the means by which their offspring would develop the adaptations of its parents. Thus, from conception onward, an organism's development is characterized by an ever-increasing ability to acquire and consume resources. Rather than debate which violent traits or behaviors are biological adaptations and which are not, we posit that all acts of physical and sexual violence have an evolutionary history associated with resource acquisition. This is not to say that such acts of violence are currently adaptive or that 
formerly adaptive behaviors cannot be recombined and refashioned for novel purposes.

Beginning with conception, there is a struggle over nutritional resources between the developing organism and its mother. Among other risky conditions, an expectant mother experiences a decrease in blood insulin as a result of a fetus-induced suppression of insulin production (Salmon, 2007). This is adaptive for the developing fetus, which is in need of glucose, but may lead to gestational diabetes for the mother. Likewise, pregnancy leads to an increase in maternal blood pressure, which is dangerous to the mother but nutritionally beneficial to her fetus (Salmon, 2007). Such parent-offspring conflicts (Trivers, 1974) may have contributed to high rates of maternal mortality, miscarriage, and stillbirth throughout human history and in parts of the developing world today.

As an infant develops, its struggle to acquire nutritional resources may take increasing tolls on its mother and on its current and future siblings. In mammals, conflict over weaning is a classic example (Salmon, 2007; Trivers, 1974). Throughout the weaning period, an infant is adaptively motivated to extract more milk than the mother is willing to apportion. Extracting the maximum amount of milk from the mother is an effective way for the infant to acquire valuable nutrients at minimal cost. The mother, on the other hand, is adaptively motivated to minimize her apportionment of milk to the infant and to invest her energy and resources into other current or future offspring instead. Sibling rivalry over access to parental resources is a related phenomenon that occurs at many dinner tables and playgrounds. Violent conflicts between adult human siblings over parental resources occur as well and may be exacerbated by the accumulation of family wealth, as facilitated by the rise of agriculture (Salmon, Chapter 7, this volume). Nevertheless, contrary to the preceding statements, genetic kin have similar reproductive interests and are more likely to cooperate and care for one another than for someone who is unrelated.

As humans mature through juvenility and adolescence, contexts for resource acquisition increasingly become peer oriented. It is during this formative period that an individual's personality and interaction style develop. Our social adaptations do not arise ex nihilo but are dependent upon life experience for their emergence. Thus, interaction with one's peers during childhood provides stimuli and responses that affect the development of our social adaptations. A host of factors contribute to this development, including genes, rearing influences, ecological factors, developmental history, and the contexts of group interaction. If a group of unacquainted children are made to interact with one another, hierarchical stratification based on dominance occurs rather quickly (Plusquellec, Francois, Boivin, Perusse, \& Tremblay, 2007; Savin-Williams, 1976). This stratification emerges via a bottom-up process and does not require centralized planning. Thus, some children become popular, others get shunned, and most find themselves in the middle of the social status hierarchy. A child's position in this hierarchy leads to the development of conditional adaptations (Boyce \& Ellis, 2005) that furthered the reproductive success of human ancestors who found themselves in such hierarchical positions in past environments. Because a child's hierarchical position is determined relative to the position of his or her peers, most children develop a combination of submissiveness- and dominance-oriented adaptations, as each child encounters settings in which he or she is either more submissive or more dominant relative to his or her peers (e.g., school, camp, karate class, etc.). Inherited characteristics and contextual factors are also responsible for the formation of stable personalities and dispositions across contexts (Weiss, King, \& Figueredo, 2000). The processes of hierarchical status formation and the development of personality traits specific to one's position within that hierarchy can be framed in the language of game theory and evolutionary biology as the development of "evolutionarily stable strategies" (Axelrod, 2006; Dawkins, 1976).

A child's hierarchical position determines his or her access to survival-related or (for older children and young adults) reproductively relevant resources. In Western cultures, where food, clothing, and shelter are generally available, children mostly compete for the approval of their peers. Peer approval is important for the formation of long-term cooperative relationships and the future exchange of resources. Likewise, social popularity in childhood may be predictive of future reproductive success in adolescence (Pellegrini \& Long, 2003; Veenstra, Lindenberg, Munniksma, \& Dijkstra, 2010). Children employ a host of strategies to acquire material and social resources within peer groups. One of these strategies is bullying, or the repeated harming of a weaker individual by a more powerful individual (Volk, Camilleri, Dane, \& Marini, Chapter 16, this volume). In povertystricken contexts, the consequences of being victimized by a bully may be more than just the loss of one's lunch money. Bullying may have been a successful 
strategy by which our juvenile and adolescent ancestors acquired the nutritional and social resources needed for survival and reproduction. Although bullying is one of a few strategies employed by children and adolescents, and although there are individual and situational differences in the use of this strategy (e.g., children who employ a combination of bullying and coalition building are of a higher social status than children who employ only one of the strategies; see Volk et al., Chapter 16, this volume), the historical and contemporary cross-cultural presence of bullying hints at its adaptive role in resource acquisition.

Men achieve greater reproductive success by being socially dominant and aggressive, as they can thereby acquire more female sexual partners. Women, on the other hand, are more likely to use indirect forms of aggression to acquire high-status mates, such as talking behind a female rival's back in order to disparage her looks or sexual reputation (see Volk et al., Chapter 16, this volume). Although there are more similarities between the sexes than there are differences, most acts of physical violence, sexual violence, war, and genocide are perpetrated by men (Daly \& Wilson, 1988). Therefore, males, more than females, should exhibit the development of cruel behaviors such as violent bullying in childhood. At a proximal level, the development of behavioral repertoires depends on the principles of operant conditioning, whereby behaviors that are reinforced by some physiological reward (perhaps regulated by dopamine) will be exhibited more often when triggered by particular stimuli associated with that reward. The neurological correlates of operant conditioning entail the strengthening of synapses between neurons detecting particular stimuli (e.g., signs of vulnerability in an individual) and neurons responsible for initiating a conditioned behavioral response to such stimuli (e.g., harassment or torture of that individual). The proximal development of violent bullying, and male aggression in general, may be characterized by such a process. This process highlights our previous point that adaptations are never preformed but depend on contextual factors for their emergence. It may be that males are more physiologically rewarded for cruelty than are females and so are more easily conditioned to engage in it. Even when threatened with punishment or the loss of resources, such children and adolescents may nevertheless engage in cruelty as it may be associated with an internal sensation of pleasure. Such individuals may be diagnosed with oppositional defiant disorder as children and antisocial personality disorder as adults-disorders characterized by a lack of concern for the well-being of others and sometimes even the positive enjoyment of others' distress.

The evolution and development of cruelty and the associated pleasure that some individuals may derive from such behavior are certainly disturbing. That such behavior may have been adaptive in certain contexts, however, does not mean that it has a scientific stamp of approval. On the contrary, approaches to remedy such behavior must take into account its evolutionary and developmental origins. Parents and educators, for instance, must learn to recognize children and adolescents who derive pleasure from inflicting pain on humans and nonhuman animals (for an evolutionary discussion of animal cruelty, see Patterson-Kane \& Piper, Chapter 15, this volume) and must somehow dissociate cruel behavior from any internal or external rewards that may be derived from it. An evolutionary paradigm may be useful in this endeavor as it may help to identify contexts in which cruelty is more likely to be exhibitedthat is, during competition over reproductively relevant resources. However, situational predictors may not be enough because individuals may be cruel for seemingly intangible rewards, such as an internal feeling of pleasure. Thus, attempts must be made to identify individuals who are more likely to be cruel due to dispositional traits exhibited across different contexts. Heritable factors may explain much of the difference in individual cruelty within a population and the use of behavioral genetic models, genetic screening, and neuroimaging technologies may help to identify and provide treatment for at-risk individuals. As opposed to treating the symptoms of cruelty, such an approach aims to cut it at its developmental roots. Therefore, if we want to live in a more humane society, we must not shy away from employing the tools of modern science to get us there.

\section{Puberty and Beyond}

An important paradigm for studying the relationship between evolution and development is life history theory (LHT; Hill \& Kaplan, 1999). LHT posits that every developmental stage of an organism is characterized by different reproductive costs and benefits. What this means is that individuals may develop new adaptations and grow out of old ones as they mature. For example, the most immediate concern for an infant is to acquire nutritional resources. Thus, infants develop adaptations such as lovability, cuteness, and eye gazing, all designed by 
selection to assist them in acquiring nutritional and social resources from their caretakers. However, as individuals approach puberty, they develop adaptations designed to acquire reproductive resources (i.e., mates). In addition to species-typical reproductive development during puberty, both sexes develop secondary sexual characteristics; most men develop increased body hair, upper-body strength, aggression, and an interest in casual sex, while most women develop breasts, buttocks, and a desire for long-term relationships. Some childhood adaptations may still be present and functional (e.g., eye gazing), while others disappear (e.g., infantile features associated with "cuteness"), but puberty marks the emergence of new adaptations designed for mating and childrearing.

With the onset of puberty, aggression and cruelty may become linked with sexual gratification (Malamuth, Check, \& Briere, 1986). This phenomenon is witnessed in the most depraved of human behaviors, such as rape and serial killing. The killing of a sexual partner is unlikely to represent an evolutionarily adaptive behavior (see Goetz \& Romero, Chapter 4, this volume), but there may be a link between sex and violence (especially in men) and rape may have ensured reproductive success for some of our male ancestors. Thus, cases of sexually motivated homicide may be by-products of evolved sexually aggressive male adaptations.

Not every emotion can occur with another emotion within an individual's psychology at the same time because scarce physiological and neurological resources are used to fuel every emotional expression. The basal ganglia may play the proximal role of neural manager by only apportioning neurological resources to cognitive and affective states that are the most biologically urgent within an individual's particular context (Redgrave, Prescott, \& Gurney, 1999). For example, an individual is usually not both angry and happy at the same time. However, some emotional states do co-occur, and we may assume that they were either positively selected to co-occur in our evolutionary history, or that their co-occurrence was not selected against. An example of such a co-occurrence may be the presence of both sexual jealousy and anger in males who perpetrate intimate partner violence (Goetz \& Romero, Chapter 4, this volume). Another cooccurrence may exist between aggression and sexual motivation. In the following paragraphs, we speculate as to whether there is a psychological link between aggression and sexual motivation/gratification and, if so, we discuss some possibilities as to what reproductive advantages this link may have provided for our male ancestors.

One argument in favor of the aggression-sexual motivation link is that sexual motivation is so common in instances of aggression. Testosterone is associated with an increase in both sexual arousal and aggression in men and women (Glina, 2004; Hermans, Ramsey, \& van Honk, 2008; Olweus, Mattson, Schalling, \& Low, 1988; Tuiten et al., 2000). Furthermore, most instances of global violence and homicide are perpetrated by young men against other young men (Daly \& Wilson, 1988), the same demographic that is disproportionately represented in militaries and coalitional combat units across communities and generations (though most generals, bureaucrats, politicians, leaders, and other "behind the scenes" individuals are usually older; see Browne, Chapter 22, this volume). From an evolutionary perspective, the fact that violence is mostly perpetrated by young men against other young men is not surprising. Men must compete aggressively with other men if they want to gain access to women-a scarce reproductive resource. Thus, sexual motivation may sometimes trigger aggression or cruelty in men. What may be surprising, however, is that men may have evolved a propensity to act aggressively during sexual encounters. Aggression and cruelty pose substantial fitness costs on men's reproductive success if enacted during sexual reproduction, as the mother of their offspring could be injured or killed in such an encounter. That aggression and sexual motivation can simultaneously occupy men's psychology suggests a selective advantage for the link between these two emotional states, an advantage that outweighed whatever fitness costs may have been paid by ancestral men due to the injury or death of their sexual partners.

Assuming the existence of a positively selected link in men between aggression and sexual behavior, we next speculate about the relevant selection pressures that may have led to its evolution. Our discussion will center on two topics from evolutionary biology: sexual conflict and sexual selection. Sexual conflict arises whenever the reproductive interests of one sex exact a cost on the reproductive interests of the other sex (Chapman, Arnqvist, Bangham, \& Rowe, 2003). A common result of sexual conflict is a coevolutionary arms race, whereby an adaptation that benefits one sex's reproductive interests but harms the other sex's reproductive interests, leads to the evolution of a defensive or an offensive counteradaptation in the other sex. These coevolutionary relationships can go on indefinitely, sometimes 
intensifying, other times subsiding. There is much evidence that such a relationship exists between males and females across many different species, including humans. For example, because of females' reluctance to engage in short-term mating due to the costs of maternal investment, males often evolve counteradaptations aimed at circumventing female sexual defenses. Such male adaptations are usually met with counteradaptations in females aimed at further restricting males' sexual access, and so a coevolutionary arms race is born. In most species, males and females need each other to reproduce, and so the majority of coevolutionary relationships between males and females are cooperative. However, there is now mounting evidence for the adaptive value of some forms of sexual coercion in humans (for a review, see Camilleri, Chapter 11, this volume). Thornhill and Palmer (2000) were initially decried for their popularization of the idea that rape may be an adaptive strategy by which some men pursue their reproductive interests. From the ashes of the ensuing controversy arose much evidence in support of an adaptive function of sexual coercion by men of women. For example, a man is more likely to sexually coerce his female intimate partner if he suspects her of sexual infidelity, as her sexual infidelity may increase the risk of rival sperm competing inside of her reproductive tract (Goetz \& Romero, Chapter 4, this volume). Furthermore, there is evidence that women may have evolved counteradaptations to deter male sexual coercion, such as being extremely cautious and wary of strange men during ovulation (McKibbin \& Shackelford, 2011). Of course, that rape may result from male adaptations does not make it moral or just. The take-home lesson is that we must be careful to not evaluate any controversial or extraordinary scientific findings on the basis of our initial emotional reactions.

One can now see how sexual conflict may lead to a link between sexual behavior and aggression in men. If a woman is reluctant to have sex with a man, then it may be to the man's reproductive advantage to have sex with her by force. Therefore, it may have been reproductively beneficial for some ancestral men to exhibit sexual arousal alongside aggressive behavior, provided that this aggressive behavior was mostly nonlethal to ancestral women. Even in contexts of apparently "consensual" sex, ancestral men may have benefited reproductively by aggressively initiating or prolonging a sexual encounter.

Most men are not rapists, and the use of a sexually coercive strategy is limited to a few contexts. Thus, the link between sexual arousal and aggressive behavior in men requires an additional evolutionary explanation. Although speculative, the concept of sexual selection may supplement our understanding of the co-occurrence of male sexual arousal and aggression. Sexual selection entails the evolution of traits that are seemingly inessential for survival, be it the peacock's tail, or men's propensity to spend much of their paychecks on shiny objects for women (Darwin, 1871; Miller, 2000). Such traits evolve because members of the other sex find them sexually attractive. That such traits are attractive is attributable to what they signal to members of the other sex: I am genetically and developmentally healthy enough to produce and maintain these traits (or procure these objects) and you should mate with me if you want your offspring to be as healthy, sexy, and resourceful as me (see Zahavi \& Zahavi, 1996). Therefore, men's standings on these traits provide excellent criteria by which women judge the anatomical, physiological, and psychological states of their suitors. We hypothesize that the co-occurrence of male sexual arousal and aggression may function as a sexually selected fitness signal for women. Perhaps men who engage in aggressive (though consensual) sexual behavior are considered attractive by women because this behavior signals physical and psychological health. Thus, only men who are in control of their bodies and minds can be sexually aroused and aggressive at the same time, without hurting or coercing their sexual partners. Such behavior requires subtlety and finesse on the part of men, and there may be a thin line between sexually aggressive consensual behavior and sexually coercive behavior. Nevertheless, that between 31\% and 57\% of women engage in erotic "rape" fantasies (Critelli \& Bivona, 2008) is evidence for the attractiveness of men's aggressive sexual behavior. Note, however, that such fantasies differ qualitatively from actual instances of rape and that women who engage in such fantasies consider actual instances of rape horrifying. More often than not, erotic rape fantasies are "...viewed as ritual displays of male dominance and female surrender" (Fisher, 1999; quoted from Critelli \& Bivona, 2008).

Sexual selection provides a less sinister explanation for the association between violence and sexual behavior in men. Nevertheless, some instances of sexual coercion, rape, and sexually motivated homicide may be the unintended results of a sexually selected co-occurrence of male sexual arousal and aggression. Furthermore, some women may be attracted to sexually coercive men because these men are more likely to sire sexually aggressive sons 
who will help to pass on their mothers' genes via forced copulations. Likewise, women may find sexually aggressive men attractive because such men may be especially successful in competitions with other men, and so will likely be able to provide for their families. That sexual aggression may sometimes function as a costly fitness signal in the context of a courtship ritual leads us to one of the topics of the next section. In war, as well as in love, exaggerated posturing and deceptive signaling occur as frequently as outright violence.

\section{Society, Culture, and Global Conflict}

Many scholars of human evolution have argued that instances of global conflict and war result from evolved male propensities to engage in violent conflict over reproductively relevant resources (Van Vugt, Chapter 17, this volume). Indeed, one of our closest living relatives, the chimpanzees (Pan troglodytes), engage in what appears to be coalitional warfare over feeding territories and mates (Wilson \& Wrangham, 2003). A coalition of adult males may embark on scouting missions to investigate the territory of a neighboring chimpanzee community. These seemingly logistical encroachments into enemy territory can go on for some time before there is any physical violence. When opposing coalitions are evenly matched, violent coalitional conflict is usually too costly to engage in. In such encounters, members of the two coalitions engage in prolonged bouts of loud and aggressive displays that deescalate intergroup violence (Goodall, 1990). However, during conflicts between individual males within communities, prolonged displays are associated with an escalation of violence. For individual males, engaging in conflict is often necessary because it promotes sexual access to fertile females, a reproductive benefit that is often worth the cost of battle. Loud and aggressive displays between males are indicative of each male's strength and are used to assess the social status of opponents. If a likely winner can be determined ahead of time, then neither individual is likely to benefit from a further escalation of displays, much less actual violence. If rival males cannot determine the likely winner, however, then displays become more prolonged until engaging in violent conflict becomes the only alternative. Thus, prolonged aggressive displays are associated with a de-escalation of coalitional violence but with an escalation of violence between individuals. One can see how individuals may sometimes benefit by deceptively inflating or deflating the volume or aggressiveness of their displays
(Dawkins \& Krebs, 1978). For example, an individual male who inflates his displays may dissuade his competitors from engaging in violent conflict and so may deceptively acquire mates and other reproductively relevant resources. The consequences of being exposed as a fraud, however, usually prevent individuals from deceptively exaggerating their aggressive displays. On the other hand, deceptively deflating the displays of one's coalition may function to lure unwary enemies into attacking and so may hasten the demise of a weaker coalition of rivals. In humans, bluffing and calling others' bluffs may lie at the heart of diplomacy and negotiation. During the Cold War, for example, both the United States and the Soviet Union were flexing their nuclear muscles toward one another so as to prevent the other side from mounting a first strike, the cost of which would have had devastating consequences for the entire world. Similar to aggressive displays between chimpanzee coalitions, nuclear testing may have paradoxically prevented an actual nuclear war. Both countries may have benefited by deceptively inflating their arsenal so as to appear untouchable, but they risked retaliation if exposed as bluffing.

When violence occurs between chimpanzee communities, it usually involves a raid by a coalition of males from one community on a lone member of another community. Such an attack is vividly portrayed by Jane Goodall (1990) in Through a Window:

Humphrey [a member of the attacking group] was the first to grab Godi, seizing one of his legs and throwing him to the ground. Figan, Jomeo, Sherry and Evered pounded and stamped on their victim, while Humphrey pinned him to the ground, sitting on his head and holding his legs with both hands. Goodall goes on:

Rodolf, the oldest of the Kasakela males, hit and bit at the hapless victim whenever he saw an opening and Gigi, who was also present, charged back and forth around the melee. All the chimpanzees were screaming loudly, Godi in terror and pain, the aggressors in a state of enraged frenzy (pp. 104-105).

Godi subsequently died from his wounds. Such attacks by members of one chimpanzee community against another are not random but serve key biological functions, such as the conquest of fertile land, fertile females, or both (Wilson \& Wrangham, 2003). Instances of cannibalism have also been reported among chimpanzees, indicating that the lack of food was perhaps one of the selection pressures 
responsible for the evolution of primate violence (Goodall, 1990; Wilson, Wallauer, \& Pusey, 2004). Cannibalism has similarly been used as a weapon of war by humans living in tribal societies (Lambert, Chapter 19, this volume). Though different, there are similarities between male coalitional violence in chimpanzees and male-perpetrated human warfare, suggesting that male coalitional violence was practiced by the common ancestor of humans and chimpanzees. Whether this is true is still a topic of debate.

To understand the emergence of human warfare, we must first examine the emergence of coalitional behavior, which necessitates a discussion of cooperation. Ironically, without cooperative coalitions, large-scale warfare and genocide would not occur. Cooperative behavior between conspecifics, alongside competitive behavior, is also a product of evolution, and it must have been reproductively advantageous to ancestral individuals to account for the outlay of time and resources on conspecifics. Favoring one's genetic relatives over unrelated conspecifics is a common example of cooperation in nature. For example, ants and termites that are part of the infertile "soldier" caste may nevertheless achieve reproductive success by sacrificing themselves in conflict against rival ant and termite populations. Such sacrifices occur because the resources gained (territory and slaves) benefit the queen of the conquering colony-usually the only colony member that is fertile. Thus, by sacrificing their lives for the colony, infertile soldiers can indirectly spread their genes via their queen. Small-scale tribal warfare in humans is often based on genetic relatedness between the male warriors and between the warriors and the rest of the tribe. Even in modern military and terror-cell settings-where soldiers or terror recruits are usually not genetic relativeskinship-based terminology is often used to cement each soldier's or jihadist's commitment to his brother in arms.

While ants and termites get their marching orders via pheromones, cooperative coalitions of human warriors use other modes of communication. Kinship-based terms such as brother may be useful for military cohesion, but cooperation between humans is not only based on genetic relatedness. Most evolutionary explanations for cooperation between unrelated conspecifics involve various types of reciprocity, or the practice of "you scratch my back, I'll scratch yours." Reciprocity can evolve when organisms within a population encounter one another over a prolonged and indefinite period, making long-term cooperation adaptive in such contexts (Axelrod, 2006; Trivers, 1971). Reciprocity can evolve as an indirect strategy, as when individuals with helpful and generous personalities are incidentally rewarded for their help and generosity, and as a direct strategy, as when individuals explicitly expect reimbursement for prior favors. Direct reciprocity is practiced mostly by socially complex organisms with sophisticated nervous systemsorganisms who can recognize each other and who can remember the cooperative or uncooperative nature of each relationship. Both direct and indirect reciprocity are practiced by humans and other primates and both set the stage for the emergence of coalitional warfare. Coalitions, however, are more than just aggregates of dyadic relationships based on reciprocity and are better understood from the perspective of group dynamics.

Because selection is stronger on individuals than it is on groups, participating in groups or in grouplevel behavior must benefit the reproductive interests of individual group members. Animals such as goats and sheep, for example, can lower their risk of being attacked by a predator if they travel together in a herd, as individuals are less likely to be attacked if they surround themselves with their conspecifics. As the saying goes, "You don't have to outrun the bear, just the other guy who's running away." Coalitions, however, are not herds, in that they involve the sophisticated coordination of behavior aimed at achieving a collective goal. A cooperative coalition can often extract more ecological resources per individual than if each individual was to go it alone, and so group behavior may sometimes be favored by selection. Sophisticated group behavior can emerge via a bottom-up process with no centralized planning. Because each individual follows a few simple rules in response to local stimuli, sophisticated group behavior can evolve and develop faster than expected. Once group dynamics emerge, they can influence individuals to behave differently than they would have if they were not part of a group. For instance, otherwise caring and thoughtful people can engage in shockingly callous and ignorant behavior when in a group, as studies in diffusion of responsibility and groupthink have demonstrated (Darley \& Latane, 1968; McCauley, 1989). The risks of engaging in such behaviors are lessened by the presence of others who are also engaging in such behaviors, and the benefits associated with the acquisition of reproductively relevant resources may be immense. Thus, instances of looting, raping, and ethnic cleansing are often perpetrated by groups of 
individuals, as during the lethal raids on Eastern European Jews in the 19th and 20th centuries, campaigns of extermination by German and Japanese troops and widespread sexual violence by Russian troops during World War II, and gang rape and genocide in the Balkans and in war-ravaged parts of Africa more recently. Military culture appears to be especially conducive to the perpetration of sexual violence by male soldiers (Morris, 1996). Thus, for our male ancestors, warfare may have been an acceptable venue in which they could pursue their reproductive interests by raping outgroup women with impunity.

Although group-perpetrated violence can arise without any centralization, charismatic and totalitarian leaders are especially effective at directing group behavior toward horrendous acts of violence and cruelty. The manipulation of one organism by another is a cross-species phenomenon and can be best understood with Dawkins's concept of the extended phenotype (Dawkins, 1982). This concept posits that a phenotype (in contrast to the genotype, the phenotype is that property of an organism which is the product of its genes and its nongenetic environment-usually restricted to an organism's bodily frame) does not end with the organism's physical body. Thus, anthills and termite mounds are ant and termite phenotypes, even though they are not parts of ant and termite bodies. Similarly, organisms can evolve manipulative adaptations by which they control the behavior of other organisms-that is, using other organisms as extended phenotypes. For example, our coughing and sneezing can be seen as an adaptive reaction on the part of our bodies to rid ourselves of viruses. Taken from the perspective of a virus, however, our coughing and sneezing may be the best avenues by which it can spread and infect other humans. This makes us, and our coughing and sneezing in particular, extended phenotypic viral adaptations. With the aid of behavioral and psychological mimicry (Chartrand \& Bargh, 1999), pheromones, verbal and nonverbal expressions, emotions, ideas, beliefs, and values, humans can manipulate the behavior of other humans in an extended phenotypic fashion and can thereby acquire reproductively relevant resources. Groups of individuals are especially vulnerable to exploitation due to the decrease in self-consciousness that accompanies deindividuation (i.e., the losing of one's self-identity within a group; Morris, 1996).

Manipulators are not always as charismatic or oratorical as was Hitler; they can be as bland and monotonous as convicted child rapist Warren Jeffs, the leader of a polygamist Mormon sect in Utah (CNN Wire Staff, 2011). Jeffs was able to seduce young girls into being his wives and concubines not through charm but through the use of inherited status, religious ideas, and sacred values. This leads us to a discussion of human culture and its relationship to human evolution. For humans, culture provides the symbolic mechanisms by which we can pursue our reproductive interests while communicating our commitment to the larger coalition. Commitment to religious and political coalitions can be communicated by following costly dietary laws, enacting complex rituals, brandishing emotional displays (e.g., having mystical visions and revelations), undergoing reproductively harmful genital mutilation, or risking injury and death in violent coalitional conflict (Atran, 2002; Wilson, 2008). Individuals who cement their commitment to a coalition by enacting such costly displays in front of coalition members may reap long-term reproductive benefits by being part of the coalition. Without cooperative coalitions based on cultural beliefs or symbols, there would be no modern civilization. Thus, a society that is too large to be united by kinship or reciprocity may nevertheless pursue common goals by uniting behind a symbol, a tradition, a moralizing god, or a philosophy. It appears that nothing unites individuals as much as beliefs in the supernatural. Individuals are drawn to minimally counterintuitive beliefs (i.e., beliefs that are realistic enough to be memorable yet strange enough to be attention grabbing-for instance, a god with human-like thoughts and emotions who is also invisible and omnipotent; Atran, 2002). Such beliefs are at the heart of tribal and modern religions and may function to unite individuals into a community of cooperative alliances with large numbers of unrelated individuals. These large-scale coalitions can be reproductively beneficial for some individuals who can thereby acquire social support and longterm access to reproductively relevant resources, including mates. At times, however, manipulators may exploit shared cultural symbols by convincing others to engage in costly acts of group commitment that benefit manipulators but inflict costs on the rest of the community. In such instances, the manipulated group or community can be considered the extended phenotype of the manipulator. Manipulators can thus acquire reproductively relevant resources such as food, territory, money, and mates. The consequences of such instances of group manipulation can range from losing one's money to a religious charlatan, to the instigation of unlawful 
military campaigns, terrorism, and genocide under the banner of religious or political symbols and ideas.

Cultural beliefs and values have an interesting effect on human evolution. Through culture, modes of behavior may be inherited that may otherwise take millions of years to evolve via the random mutation and natural selection of genes. The mechanisms by which culture affects human behavior and evolution may be illuminated by the somewhat different phenomenon of mother rats licking their offspring. Licking behavior, like human culture, can be inherited across generations without altering the genes of individual rats. Thus, if a newborn female rat whose birth mother was not a licker is raised by a foster mother who licks her pups, the rat will subsequently lick her own pups when she becomes a mother (Meaney, 2001). Having been licked is associated with benefits such as sociability and lowered anxiety (Meaney, 2001). Similarly, the linguistic and cultural environment experienced by humans during childhood may affect their own adult behavior and the behavior of their children. For example, men from populations with a long history of resource scarcity and lawlessness (e.g., the descendants of the Scotch-Irish settlers in the southern and western parts of the United States, and men from herding cultures throughout the Middle East) often develop a "culture of honor" centered on the aggressive defense of one's reputation and manhood (see Brown \& Osterman, Chapter 13, this volume). In contexts of resource scarcity and a lack of law enforcement, individuals (particularly men) must develop a reputation for toughness and vengefulness if they are to acquire and maintain reproductively relevant resources, including women. Thus, aggressive behavior associated with a culture of honor may become culturally inherited and may remain within a population even if the original contexts that spawned it have been long gone.

The emergent effects of genetic and cultural evolution can be difficult to predict, as genes and cultural products dynamically interact and cause evolution to spiral into unexplored territories (Cochran \& Harpending, 2009). Similarly, much of our ancestral genetic and cultural inheritance may be combined and recombined in many ways that differ from ancestral contexts. Thus, military recruits may take advantage of the "culture of honor" mindset of poor young men by convincing them that their country's honor is on the line and that lawless savages are threatening their family and their resources. When kinship-based terms, sacred values, and religious beliefs are thrown into the mix, individuals may become ready to sacrifice their lives and engage in unimaginable physical and sexual violence. From there, group dynamics and extended phenotypic manipulation of militaries and terror cells may lead to destruction on a global scale. Military conflicts are sometimes inevitable and a just war can be waged. Our evolutionary legacy, however, may not be ready for its lethal combination with weapons of mass destruction. In the following section, we call for an approach by which individuals can understand the evolutionary antecedents of their behavior and the effects of their behavior on the rest of society.

\section{Evolutionary Consciousness}

In this section, we do not confine ourselves to abstract evolutionary explanations of human violence. Instead, we personalize some of the ideas discussed in previous sections to better understand our own thoughts, emotions, and behaviors. We do not advocate for any one social or political policy or ideology, save for our deep commitment and endorsement of evolutionary science and its application to issues of human concern. In discussing personal responsibility from an evolutionary perspective, we are cognizant of the fact that individual-level behavior affects societal-level phenomena. Thus, our primary goal is to unveil the extent to which our actions not only influence our immediate context but also society and the world at large. The human extended phenotype may thus be the most extended of any species, as our technological and cultural innovations enable us to influence lives and ecosystems on a global scale. With such power, ignorance of our evolved nature-its strengths and its weaknesses-is morally inexcusable. Therefore, our secondary goal is to help ourselves and our readers to develop an evolutionary consciousness. By evolutionary consciousness, we are not referring to any mystical or new age concept plucked out of a self-help book. Instead, being evolutionarily conscious means being aware of the evolutionary origins of our drives, motivations, desires, emotions, and thoughts. Such awareness may better enable us to understand the moral and ethical implications of our actions and decisions. In advocating for an evolutionary consciousness, we do not posit any code of conduct or ethics. Instead, we hope to empower the reader to make his or her own moral decisions in an evolutionarily informed way. We are not naïve and understand that the application of evolutionary principles to personal matters is not without 
danger, as social Darwinism and government-instituted eugenics have proven within the last century. Nonetheless, the dangers of not viewing ourselves through an evolutionary lens may be much greater and the price of ignorance may be paid by the unintended effects of our own choices and the choices of others. Thus, we tentatively embark on an exploration of what an evolutionary consciousness is and how it might be applied to matters both personal and public. Our discussion is only the beginning. It is up to educators and policy makers to ensure that no child is made ignorant of the beauty and relevance of biological evolution. Especially in the United States, where science teachers are ridiculed and censured by Evangelical interests, no time is more pressing than now. If we are to understand the biological roots of sexism, xenophobia, war, and genocide, then our society must accept and embrace the evolutionary paradigm.

To understand what an evolutionary consciousness may entail, we return to the concept of the extended phenotype. We assume that most readers of this chapter are not rapists, murderers, and warmongers. However, every decision that we make, as innocuous as it may seem, may contribute to global instances of rape, murder, and war. The reason for this is that over the past 10,000 years (Cochran \& Harpending, 2009), human agriculture, technology, and global interconnectedness have extended our phenotypic effects to unprecedented scales. For better or worse, modern civilization has immensely magnified our influence on each other and on our environment. From the products and services that we purchase, to the political, religious, and philosophical stances that we take, the effects of our reproductive interests have been felt by billions of humans and innumerable other species across the globe. Next, we discuss an example of a reproductively relevant resource-the diamond-whose consumption has led to the rape and slaughter of countless individuals and ecosystems. Though not the only such resource (some others include fossil fuels whose extraction supports brutal dictatorships in the Middle East, African and Asian goods manufactured by child-slave labor, and delicacies and products procured from endangered species), the purchasing of diamonds exemplifies an instance in which our reproductive interests as consumers are pitted against the survival and well-being of other humans. We do not focus our discussion on the effects of our decisions on nonhuman animals and ecologies, but the arguments that we make can be readily applied to both. Our goal is to inspire an awareness of the extended phenotypic effects of our daily decisions. This awareness we term "evolutionary consciousness." We hope that such an evolutionary consciousness can enable us to modify our behavior in order to reduce the suffering of those affected by it. However, this hope may carry too much optimism. At the very least, an evolutionary consciousness can enrich our understanding of ourselves, our world, and of the effects that we have on our world. If for no other reason than this, the development of an evolutionary consciousness is a worthy endeavor. Of course, violent sociopaths may also be capable of developing an evolutionary consciousness and benefiting from it - a worrisome possibility for which we admit we have no antidote. By focusing on the ethical implications of human decisions, however, we hope that our discussion can better empower the prosocial among us to cast aside some of the destructive effects of their extended phenotypes.

Presumably, most readers of this chapter do not have to compete for resources that are essential for survival, such as food, water, and shelter. However, many of us engage in economic competition for other reproductively relevant resources that are believed to be useful in acquiring sexual partners, such as extravagant property and superfluous capital (Miller, 2009). This competition over nonessential resources contributes to the destruction or redirection of essential resources that are needed by millions of destitute individuals, especially those living in underdeveloped nations. For example, men in Westernized societies are culturally conditioned to communicate romantic commitment and devotion to women by buying them lavish products and services. The jewelry industry, with help from the media, has popularized the notion that nothing says "I love you" to a woman as much as a glittering diamond. Thus, many Western men believe that a diamond ring is the quintessential symbol of long-term commitment to a mate, and many Western women consider this gift a necessity for acceptance of men's marital propositions. Such displays of monogamy, however, come at the cost of millions of human lives and irreparable environmental degradation. That otherwise kind and peaceful individuals may be complicit in the genocide, rape, enslavement, and population displacement wrought by the jewelry industry in many parts of sub-Saharan Africa underscores the need for us to examine our purchasing decisions from an evolutionary perspective. Such an examination reveals that our ancient reproductive strategies have gained unprecedented 
extended phenotypic powers via their utilization of modern-day cultural innovations in technology and global business practices, as exemplified by the diamond industry. Whether such extended phenotypic uses of cultural products lead to reproductive success in modern societies is difficult to determine and, in any case, is beside the point. The point that we are making is that by being evolutionarily conscious of our reproductive behaviors and the economic decisions that they motivate, we can redirect our mating efforts toward more prosocial avenues that do not entail the exploitation of third-world populations and environments. For example, a diamond is used to signal commitment to one's romantic partner. This signal is not only directed toward one's partner but also toward members of one's community (e.g., friends, family, acquaintances, and in-laws) who are used as guarantors to insure that one lives up to the commitment symbolized by that diamond. The same signaling function can be achieved by resources whose global impact is less destructive, and possibly even constructive, such as expensive custom-made jewelry produced by local artisans with materials that are just as sturdy and beautiful but whose extraction and synthesis did not entail the spillage of blood. Thus, rather than attempting to bring down the monolithic jewelry industry, individuals can fundamentally change the marketplace of reproductive goods and services by changing their consumption patterns in a bottomup fashion.

As discussed in the previous section, human thoughts, emotions, and behaviors can become drastically altered when an individual finds himself or herself surrounded by others. Thus, forms of physical and sexual violence inconceivable by isolated individuals become acceptable in a group setting. For group behavior to emerge, however, one does not have to be in direct contact with other group members as one is in the military or in a soccer riot. Even when in isolation, group mentality may lead one to support religious and political policies that enact brutality and environmental degradation. As discussed by Hudson and Den Boer (Chapter 18, this volume), patriarchal traditions and institutions may be effective cultural tools by which cooperative male coalitions exert extended phenotypic control over women's reproductive interests. The disastrous effects of such male dominance are not only felt by women but by all of society, as patriarchal cultures exhibit increased rates of internal and external violence and discord. Thus, when one supports a religious tradition or a political party that curtails women's reproductive freedom (e.g., policies that often go under code words such as "right to life" or "family values"), one's adaptations that normally function to bring about intragroup reciprocity, group coordination toward resource acquisition, and emotional belongingness to a social network may indirectly bring about deplorable outcomes. Many kind-hearted Catholics, for example, are complicit in the death of millions of Africans by indirectly (or directly) supporting the Catholic Church's policy of not advocating the use of condoms to stem the spread of AIDS. In the political sphere, support for some conservative policies may indirectly bring about militarism, economic and social inequality, and environmental degradation, while support for some liberal policies may lead to the appeasement of brutal despots and dictators, suppression of lifesaving agricultural innovations such as genetically modified crops, and the continuation of funding for corrupt and wasteful government institutions. By being evolutionarily conscious of our motivations for aligning ourselves with some of these groups and communities, we can help to reverse the socially and environmentally violent consequences of our support for their policies.

When thinking about an evolutionarily informed consciousness, one is easily reminded of psychoanalytic explorations of hidden drives and unsavory libidinous desires. Although there are similarities between the psychoanalytic and the modern, evolution-informed understanding of the mind (i.e., both posit that the mind is subdivided into modular processes, though to varying degrees), there are also clear differences. For example, unlike the Freudian model of the id, ego, and superego, an evolutionary conception of the mind does not posit that some mental functions are innate or "primal" while others are socialized. All psychological adaptations are innate, in the sense that they have an evolutionary history, are products of natural selection, and that the means of their construction are inherited. Furthermore, all psychological adaptations require environmental input and socialization to develop in a species-typical manner. Thus, mental adaptations that motivate behaviors as diverse as physical and sexual aggression are no more and no less "primal" than human kindness, and all require experience to develop properly. Another difference between the two traditions is that, in contrast to the psychoanalytic conception of the unconscious, one does not need years of psychoanalytic therapy filled with exercises in free association to understand one's own drives 
and desires. Though many of our mental processes are implicit and function outside of conscious awareness (Greenwald, McGhee, \& Schwartz, 1998), by examining our behavior from the perspective of resource acquisition, we can gain valuable insights into our evolved minds. For example, from one perspective, we are writing this chapter to expose readers to evolutionary ideas and hope that the scientific and philosophical frontier is thereby expanded. From an evolutionary perspective, however, our motivation in writing this chapter may stem from our desire to be cited by our academic peers or awarded with tenure by our universitiesoutcomes that may enhance our social status and help us to accumulate economic resources. Thus, developing an evolutionary consciousness does not require us to analyze our dreams but to shift our own perspective of ourselves.

The psychological struggle against one's inner demons is a common theme in world mythology and much of literature. From the Buddha to Christ, Doctor Faust to Doctor Jekyll, archetypal battles against aspects of oneself may stem from the nature of our evolved minds. Indeed, discoveries in biology, genetics, neuroscience, and psychology have unveiled just how fractionated we are. For example, our mitochondria were once free-living bacteria that invaded our single-celled ancestors and subsequently engaged in a symbiotic relationship with them, as did much of the bacteria that help us to digest our food (Emelyanov, 2001; Hooper, 2004). Likewise, much of our DNA may have been borrowed from viruses that embedded themselves into our ancestors' genomes (Belshaw et al., 2004). In fact, our genes and chromosomes sometimes pursue their own interests at the cost of our well-being, as is exemplified by instances of cancer, Down syndrome (Axelrod, 2006), and conflicts between paternal and maternal genes within an individual organism (Haig, 2000, 2006; Patten \& Haig, 2008; Úbeda \& Haig, 2003). At the neurological level, our right hands may not always know what our left hands are doing, as is shown by experiments with split-brain patients (Gazzaniga, 2005). Lastly, our modular minds, as posited by evolutionary psychologists, provide evidence for a disconnected network of psychological processes as opposed to a unitary consciousness (Kurzban, 2010). Could it be that our internal struggles with ourselves have a deep evolutionary history? How can we truly understand, much less control, ourselves if there is no real "self" to begin with? Reflecting on our own behavior and its consequences may be a start.

As with any philosophy or mindset, an evolutionary consciousness is not without dangers. Although we believe that holding false beliefs and having the need for a supernatural salvation are immeasurably more dangerous, we do not delude ourselves to the dangers that may arise from perceiving the world through an evolutionary lens. A feeling of anguish may overcome one who sees parasitism and violent coevolutionary arms races as the raison d'être of all life-anguish that is perhaps exacerbated by the knowledge that one is not in control of oneself and is possessed by conflicting agendas and influences, both internal and external. This anguish may pale in comparison to the fear of hellfire but is nonetheless worthy of attention. Realizing that your loved ones may be harboring manipulative tendencies or that your romantic relationships may be based on billion-year-old reproductive conflicts between the sexes may be somewhat disenchanting. In consolation, we say this: There is a deep feeling of satisfaction and connectedness that comes from realizing that you are part of a 3.5 billion year saga that biologically connects you to all life on Earth. In addition to traditions, rituals, folk knowledge, and other cultural practices, our ancestors possessed more wisdom than they ever imagined. Via their genetic and developmental legacy to us, they imparted clues as to who we are and where we might be going. Evolutionary consciousness is a romantic idea of the highest caliber and it makes one's love (however love may be defined) reverberate with the knowledge that a very similar feeling was present in our ancestors across millions of generations. In all likelihood, loving others was indispensable for our ancestors' survival and reproduction and may therefore be partly responsible for our very existence. In addition to love and compassion, however, aggression and violence may have been just as indispensable for our ancestors' reproductive success. Therefore, evolutionary consciousness is also a potent tool for plumbing the darkest depths of our bodies and minds, and both explains and suggests remedies for the violence that so plagues our world. Finally, evolutionary consciousness may help to guide the individual on a journey that so many other organisms have taken in the past and are taking again today. Like a compass, the theoretical and empirical framework of evolutionary science may guide us as individuals—and as a species— to the heights of our potential. 


\section{Conclusion}

We doubt that a chronically violent individual will become peaceful if his or her evolutionary consciousness is expanded. Therefore, our discussion of an evolutionary consciousness should not be read as a remedy for the violence plaguing our world but understood as an approach by which one can better appreciate the ecological and evolutionary effects of one's actions on oneself and on others. The elimination of human violence has been attempted by countless individuals and civilizations throughout the ages — to little avail—and often revolutionaries and utopians who undertake just causes in the name of "peace" become as inhumane as their enemies. Because violence is often the product of evolved mechanisms that enabled our ancestors to acquire reproductively relevant resources over millions of years, it is unlikely to disappear anytime soon. Even if resources are equally distributed within and across populations, humans are likely to find a way to compete for innumerable other resources that are useless for survival but are necessary for the procurement of sexual partners.

Violence can be a moral necessity if used to defend oneself, one's loved ones, or those who are weak or oppressed. Thus, by seeking to eliminate violence (including the propensity for war) from the human behavioral repertoire, we may be eliminating an important means of defense against murderers, rapists, and warmongers-individuals who are ready to prey upon the kindness and peacefulness of others. The reason that eliminating violence may have this effect is that nonviolent societies are vulnerable to invasion and takeover by violent individuals from within and without. Even if human violence is eliminated entirely, selection will favor the reproductive prospects of individuals whose violence would enable them to extract reproductively relevant resources from nonviolent conspecifics. On the other hand, we may be condemning our progeny to endless cycles of violence if some violence is condoned, as the maintenance of morally sanctioned violence within a population can lead to the inadvertent emergence of cruelty and sadism in subsequent generations. One might say that humanity is stuck between the Scylla and Charybdis of making ourselves defenseless against violence by eliminating it, or of doing nothing about it. This may be a false dichotomy. So far, however, there is no obvious pathway toward world peace.

Beginning with the Industrial Revolution, science and technology have blossomed to unprecedented levels. This blossoming may be somewhat equivocal, as along with modern medicine came the Atomic Age. However, death rates due to violent crime, homicide, and war are substantially lower now than they were in our ancestral past (at least in developed nations). This is partly a result of an increase in the quality of life for even the most destitute among us, highlighting the importance of making sure that all individuals have access to resources needed for survival. The relative peace and social harmony prevalent throughout the Scandinavian countries (despite the recent tragedy in Norway) is further proof that providing for everyone's basic needs may benefit all of society (Zuckerman, 2008). However, providing life-sustaining resources to the needy without dealing with the problem of population is fruitless. In later versions of his Essay on Population, Thomas Malthus - perhaps influenced by his position as an Anglican curate or by his Colonialist sentimentsstressed that encouraging the lower classes to engage in moral restraint was the best remedy for unsustainable population growth. Even for Malthus's time, encouraging poor young men to become celibate may have been a bit naïve (though not too naïve to prevent the Catholic Church from doing so). However, Malthus was right to encourage the delaying of marriage until one had accrued enough resources to sustain a family. For instance, in 18th-century England-Malthus's own settingthe increase in women's marrying age may have been responsible for the educational and economic empowerment of women and the related decrease in male-wrought violence and instability throughout much of Northwestern Europe (see Hudson \& Den Boer, Chapter 18, this volume). Couple this with modern birth control practices and society need not resort to moral restraint to live sustainably.

With the Industrial Revolution also came a kind of "sublimation" of the violence that was previously perpetrated over reproductively relevant resources. Thus, men are less likely to wage war or engage in Wild West-style shootouts to acquire mates (except in poverty-stricken environments; see Kruger \& Fitzgerald, Chapter 10, this volume) than they are to aggressively pursue their reproductive interests in coalitional behavior on the basketball court or on Wall Street (though the latter economic and reproductive playground may be causing much of the structural violence responsible for income inequalities throughout the world). Of course, we are not implying that "shooting hoops" can free the world from senseless brutality, but we do suggest that 
modifying the contexts wherein which men compete for reproductively relevant resources may help to decrease levels of violence. Our efforts may also be supplemented with the best tools that modern science has to offer. Along with behavioral modification approaches, future innovations in fields such as genetics and cognitive neuroscience may help to remedy the scourge of human violence on an individual-by-individual basis. In doing so, however, we must confront the ethical and moral dilemma of whether we should value the rights of society over the rights of the individual. Hopefully, we will be able to strike an acceptable balance.

\section{References}

Atran, S. (2002). In gods we trust: The evolutionary landscape of religion. Oxford, England: Oxford University Press.

Axelrod, R. (2006). The evolution of cooperation. New York: Basic Books.

Belshaw, R., Pereira, V., Katzourakis, A., Talbot, G., Paces, J., Burt, A., \& Tristem, M. (2004). Long-term reinfection of the human genome by endogenous retroviruses. Proceedings of the National Academy of Sciences USA, 101(14), 4894-4899.

Bjorklund, D. F., \& Pellegrini, A. D. (2002). The origins of human nature: Evolutionary developmental psychology. Washington, DC: American Psychological Association.

Boyce, W. T., \& Ellis, B. J. (2005). Biological sensitivity to context: I. An evolutionary- developmental theory of the origins and functions of stress reactivity. Development and Psychopathology, 17, 271-301.

Buss, D. M., \& Shackelford, T. K. (1997). Human aggression in evolutionary psychological perspective. Clinical Psychology Review, 17(6), 605-619.

Carroll, S. B. (2005). Endless forms most beautiful: The new science of evo devo. New York: W. W. Norton.

Chang, E. F., \& Merzenich, M. M. (2003). Environmental noise retards auditory cortical development. Science, 300(5618), 498-502.

Chapman, T., Arnqvist, G., Bangham, J., \& Rowe, L. (2003). Sexual conflict. Trends in Ecology and Evolution, 18(1), 41-47.

Chartrand, T. L., \& Bargh, J. A. (1999). The chameleon effect: The perception-behavior link and

social interaction. Journal of Personality and Social Psychology, 76(6), 893-910.

Cochran, G., \& Harpending, H. (2009). The 10,000 year explosion: How civilization accelerated human evolution. New York: Basic Books.

Critelli, J. W., \& Bivona, J. M. (2008). Women's erotic rape fantasies: An evaluation of theory and research. Journal of Sex Research, 45(1), 57-70.

CNN Wire Staff. (2011, August 12). Court releases Warren Jeffs audio sex tapes. CNN. Retrieved December 2011, from: http://articles.cnn.com/2011-08-12/justice/texas.polygamist. jeffs_1_warren-jeffs-sexual-assault-fundamentalist-church?_ $s=$ PM:CRIME

Daly, M., \& Wilson, M. (1988). Homicide. Hawthorne, NY: Aldine de Gruyter.

Darley, J. M., \& Latane, B. (1968). Bystander intervention in emergencies: Diffusion of responsibility. Journal of Personality and Social Psychology, 8(4), 377-383.
Darwin, C. (1871). The descent of man, and selection in relation to sex. London: Charles Murray.

Dawkins, R. (1976). The selfish gene. Oxford, England: Oxford University Press.

Dawkins, R. (1982). The extended phenotype. Oxford, England: Oxford University Press.

Dawkins, R., \& Krebs, J. R. (1978). Animal signals: Information or manipulation? In J. R. Krebs \& N. B. Davies (Eds.), Behavioral ecology: An evolutionary approach (pp. 282-309). Oxford, England: Blackwell Scientific Publications.

Emelyanov, V. V. (2001). Rickettsiaceae, rickettsia-like endosymbionts, and the origin of mitochondria. Bioscience Reports, $21,1-17$.

Fagiolini, M., Pizzorusso, T., Berardi, N., Domenici, L., \& Maffei, L. (1994). Functional postnatal development of the rat primary visual cortex and the role of visual experience: Dark rearing and monocular deprivation. Vision Research, 34, 709-720.

Fisher, H. (1999). The first sex. New York: Random House.

Gazzaniga, M. S. (2005). Forty-five years of split-brain research and still going strong. Nature Reviews Neuroscience, 6, 653-659.

Glina, S. (2004). Testosterone and erectile dysfunction. Journal of Men's Health and Gender, 1(4), 407-412.

Goodall, J. (1990). Through a window. New York: Mariner Books.

Greenwald, A. G., McGhee, D. E., \& Schwartz, J. L. K. (1998). Measuring individual differences in implicit cognition: The implicit association test. Journal of Personality and Social Psychology, 74(6), 1464-1480.

Haig, D. (2000). The kinship theory of genomic imprinting. Annual Review of Ecology and systematic, 31, 9-32.

Haig, D. (2006). Intragenomic politics. Cytogenetic and Genome Research, 113, 68-74.

Hamilton, W. D. (1964). The genetical evolution of social behavior (I and II). Journal of Theoretical Biology, 7, 1-52.

Hermans, E. J., Ramsey, N. F., \& van Honk, J. (2008). Exogenous testosterone enhances responsiveness to social threat in the neural circuitry of social aggression in humans. Biological Psychiatry, 63, 263-270.

Hill, K., \& Kaplan, H. (1999). Life history traits in humans: Theory and empirical studies. Annual Review of Anthropology, $28,397-430$.

Hooper, L. V. (2004) Bacterial contributions to mammalian gut development. Trends in Microbiology, 12(3), 129-134.

Hopfenberg, R., \& Pimentel, D. (2001). Human population numbers as a function of food supply. Environment, Development and Sustainability, 3, 1-15.

Kolbert, J. B., \& Crothers, L. M. (2003). Bullying and evolutionary psychology. Journal of School Violence, 2(3), 73-91.

Kurzban, R. (2010). Why everyone else is a hypocrite: Evolution and the modular mind. Princeton, NJ: Princeton University Press.

Malamuth, N. M., Check, J. V. P., \& Briere, J. (1986). Sexual arousal in response to aggression: Ideological, aggressive, and sexual correlates. Journal of Personality and Social Psychology, 50(2), 330-340.

McCauley, C. (1989). The nature of social influence in groupthink: Compliance and internalization. Journal of Personality and Social Psychology, 57(2), 250-260.

McKibbin, W. F., \& Shackelford, T. K. (2011). Women's avoidance of rape. Aggression and Violent Behavior, 16, 437-443.

McLaughlin, E. C. (2011). From "privileged" youth to afternoon of carnage. CNN. Retrieved December 2011, from: http:// 
www.cnn.com/2011/WORLD/europe/07/27/norway. breivik.chronology/index.html

Meaney, M. J. (2001). Maternal care, gene expression, and the transmission of individual differences in stress reactivity across generations. Annual Review of Neuroscience, 24, $1161-1192$.

Miller, G. F. (2000). The mating mind: How sexual choice shaped the evolution of human nature. London: Heinemann.

Miller, G. F. (2009). Spent: Sex, evolution, and consumer behavior. New York: Viking.

Morris, M. (1996). By force of arms: Rape, war, and military culture. Duke Law Journal, 45(4), 651-781.

Nelson, C. A. (2001). The development and neural bases of face recognition. Infant and Child Development, 10(1-2), 3-18.

Olweus, D., Mattsson, A., Schalling, D., \& Low, H. (1988). Circulating testosterone levels and aggression in adolescent males: A causal analysis. Psychosomatic Medicine, 50, 261-272.

Patten, M. M., \& Haig, D. (2008). Reciprocally imprinted genes and the response to selection on one sex. Genetics, 179, 1389-1394.

Pellegrini, A. D., \& Long, J. D. (2003). A sexual selection theory of longitudinal analysis of sexual segregation and integration in early adolescence. Journal of Experimental Child Psychology, 85, 257-278.

Plusquellec, P., Francois, N., Boivin, M., Perusse, D., \& Tremblay, R. E. (2007). Dominance among unfamiliar peers starts in infancy. Infant Mental Health Journal, 23(3), 324-343.

Razek, R., Ahmed, A., \& Sidner, S. (2011, June 18). Libyan government denies rape allegations. CNN. Retrieved December 2011, from: http://www.cnn.com/2011/WORLD/africa/06/ 18/libya.rape/index.html?iref=allsearch

Redgrave, P., Prescott, T. J., \& Gurney, K. (1999). The basal ganglia: A vertebrate solution to the selection problem? Neuroscience, 89(4), 1009-1023.

Rodriguez, J. I., Palacios, J., Garcia-Alix, A., Pastor, I., \& Paniagua, R. (1988). Effects of immobilization on fetal bone development: A morphometric study in newborns with congenital neuromuscular diseases with intrauterine onset. Calcified Tissue International, 43, 335-339.

Salmon, C. A. (2007). Parent-child conflict. In C. A. Salmon \& T. K. Shackelford (Eds.), Family relationships: An evolutionary perspective (pp. 145-161). New York: Oxford University Press.

Savin-Williams, R. C. (1976). An ethological study of dominance formation and maintenance in a group of human adolescents. Child Development, 47, 972-979.

Sly, L. (2011, May 29). Apparent death of boy reinvigorates Syria's protest movement. The Washington Post. Retrieved December 2011, from: http://www.washingtonpost.com/ world/middle-east/torture-of-boy-reinvigorates-syrias-protest-movement/2011/05/29/AGPwIREH_story.html

Teague, K. (2011, August 7). Two million East African infants are now starving. The Independent. Retrieved December 2011, from: http://www.independent.co.uk/news/world/africa/twomillion-east-african-infants-are-now-starving-2333270.html

Thornhill, R., \& Palmer, C. T. (2000). A natural history of rape: Biological basis of sexual coercion. Cambridge, MA: MIT Press.

Tooby, J., \& Cosmides, L. (1992). The psychological foundations of culture. In J. H. Barkow, L. Cosmides, \& J. Tooby (Eds.), The adapted mind: Evolutionary psychology and the generation of culture (pp. 19-136). New York: Oxford University Press.

Trivers, R. (1971). The evolution of reciprocal altruism. Quarterly Review of Biology, 46, 35-57.

Trivers, R. (1972). Parental investment and sexual selection. In B. Campbell (Ed.), Sexual selection and the descent of man, 1871-1971 (pp. 136-179). Chicago: Aldine-Atherton.

Trivers, R. (1974). Parent-offspring conflict. American Zoologist, 14, 249-264.

Tuiten, A., Van Honk, J., Koppeschaar, H., Bernaards, C., Thijssen, J., \& Verbaten, R. (2000). Time course of effects of testosterone administration on sexual arousal in women. Archives of General Psychiatry, 57, 149-153.

Úbeda, F., \& Haig, D. (2003). Dividing the child: Genomic imprinting and evolutionary games. Genetica, 117, 103-110.

Veenstra, R., Lindenberg, S., Munniksma, A., \& Dijkstra, J. K. (2010). The complex relation between bullying, victimization, acceptance, and rejection: Giving special attention to status, affection, and sex differences. Child Development, 81, 480-486.

Weiss, A., King, J. E., \& Figueredo, J. (2000). The heritability of personality factors in chimpanzees (Pan troglodytes). Behavior Genetics, 30(3), 213-221.

Wilson, C. G. (2008). Male genital mutilation: An adaptation to sexual conflict. Evolution and Human Behavior, 29, 149-164.

Wilson, M. L., Wallauer, W. R., \& Pusey, A. E. (2004). New cases of intergroup violence among chimpanzees in Gombe National Park, Tanzania. International Journal of Primatology, 25(3), 523-549.

Wilson, M. L., \& Wrangham, R. W. (2003). Intergroup relations in chimpanzees. Annual Review of Anthropology, 32, 363-392.

Zahavi, A., \& Zahavi, A. (1996). The handicap principle. New York: Oxford University Press.

Zuckerman, P. (2008). Society without God: What the least religious nations can tell us about contentment. New York: New York University Press. 